\title{
SEGREGATION OF POLYGENES IN ORDERED TETRADS
}

\author{
J. A. PATEMAN* and B. T. O. LEE \\ Botany School, University of Melbourne, Australia
}

Received 25.vii.6o

\section{INTRODUCTION}

IT is commonly accepted that systems of multiple factors, polygenes, are responsible for most cases of continuous heritable variation. It has been pointed out by Mather (1949) that segregation and linkage are essential features of polygenes. The demonstration of the segregation of polygenes rests on the observed increase of variation in $F_{2}$ compared with $F_{1}$ generations and the relative variation of these and further generations.

Previous work (Pateman, I955; 1959; Lee and Pateman, 1959) has shown that size of ascospore in Neurospora crassa is controlled by a polygenic system. The experiments reported here provide a direct demonstration of the segregation of polygenes affecting ascospore size during the formation of ordered tetrads (asci) in $\mathcal{N}$. crassa.

The majority of the life cycle of $\mathcal{N}$. crassa is haploid. It is desirable to clarify the use of such terms as $P_{1}, F_{1}$ and $B_{1}$ when applied to the stages of such a life cycle. Figure I shows the degree of ploidy of all

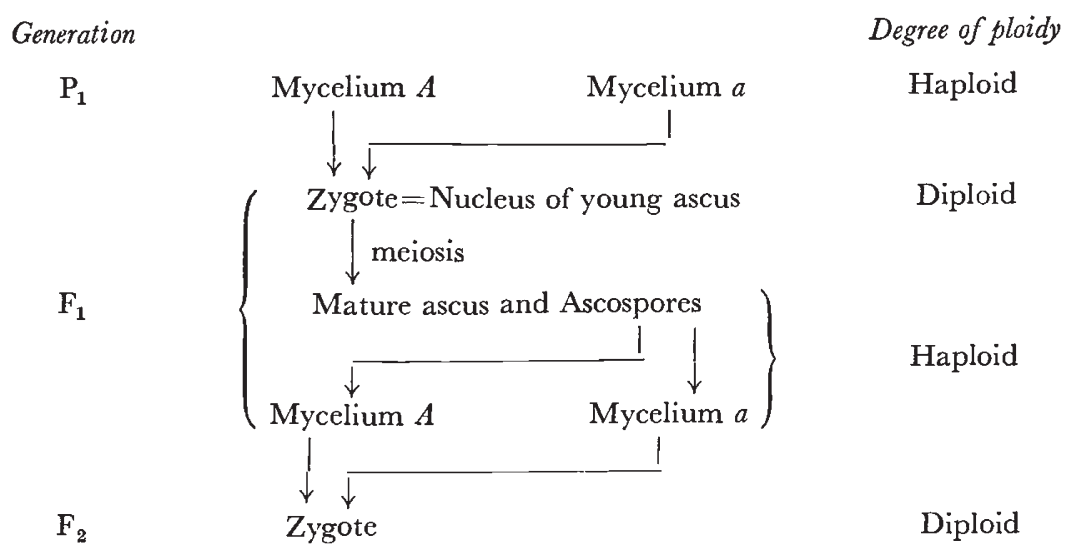

FIG. I.-Diagrammatic illustration of life cycle of $\mathcal{N}$. crassa.

relevant stages and the generation to which they are considered to belong. This usage is followed throughout this paper. A first backcross generation, $B_{1}$ is derived from a cross between an $F_{1}$ mycelium and a $\mathrm{P}_{1}$ mycelium. $A B_{2}$ generation is derived from a cross between a $B_{1}$ mycelium and a $\mathrm{P}_{1}$ mycelium.

* Present address : Department of Genetics, University of Cambridge. 


\section{METHODS}

The detailed origin of strains 232-2, 232-4, and St.L.A was described by Pateman (1959). Strains 232-2 and 232-4 were obtained from a cross between two strains at the fifteenth generation of selection for increased ascospore size. The mean length of ascospores from the cross $232-2 \times 232-4$ was $17 \cdot 76$, and the mean length of ascospores from a wild-type cross was $13 \cdot 55$, the unit of measurement being about $2 \cdot 17 \mu$. That is, the genotype built up by selection in strains 232-2 and 232-4 resulted in an increase of about 35 per cent. in mean ascospore length compared with wild-type.

In the present work a projection microscope was used to measure the ascospores, the unit of measurement being approximately $\mathrm{I} \cdot 73 \mu$. Vegetative cultures were maintained on agar slopes of Fries No. 3 medium (Beadle and Tatum, 1945). All crosses were made on agar slopes of a medium favouring sexual reproduction (Westergaard and Mitchell, 1947) and incubated at $25^{\circ} \mathrm{C}$.

\section{RESULTS}

It was not possible to demonstrate satisfactorily segregation of polygenes during the formation of $F_{1}$ asci from the cross $232-4 \times$ wildtype, since $\mathrm{F}_{1}$ ascospores are phenotypically similar to wild-type. An attempt to demonstrate polygenic segregation using crosses between the members of ascus 232 was unsuccessful, partly because any genotypic differences were small in comparison with environmental variation (Pateman, I959). Consequently, asci from backcrosses to the largespored strain 232-4 were used to demonstrate such segregation. In the formation of backcross asci the ratio of large-spored genotype to wild genotype was $3: \mathrm{I}$. When members of the backcross asci were again crossed to the large-spored strains $23^{2-2}$ or $232-4$ the ratio of largespored genotype to wild was $7: \mathrm{I}$. This preponderance permitted the phenotypic expression of the large-spored genotype. Also the presence of a small proportion of wild genotype reduced the environmental variation between replicate crosses.

The derivation of the backcross asci and the testcrosses were as follows. Three single ascospore, $F_{1}$ cultures designated 1,2 and 3 were obtained from the cross $232-4 \times$ St.L. From the backcross I $\times 232-4$, ascus I was dissected and the eight single ascospore cultures I-I to I-8 obtained. From the backcross $2 \times 232-4$ the three asci 2, 3 and 4 were obtained. From the backcross $3 \times 232-4$, asci 5 and 6 were obtained. Members of each of the six asci were crossed to either 232-2 or 232-4; the implications of the use of two "tester" strains are discussed later. Five replicates of each cross were made and fifty ascospores from each replicate were measured. The mean length of each sample of ascospores provided an estimate of the genotype of the member of the ascus. In the case of the two asci $I$ and 5 , all eight members of each were testcrossed in this way. With the other four asci only one member of each mitotic pair was testcrossed. This still permitted comparisons between each of the four meiotic products in each ascus. The results of these crosses are given in table I. In all six asci the segregation of the mating type alleles $A$ and $a$ is given. In asci 1,5 and 6 the segregation is also given of two alleles at the 
POLYGENES IN TETRADS

\begin{tabular}{|c|c|c|c|c|c|c|}
\hline \multirow{14}{*}{ 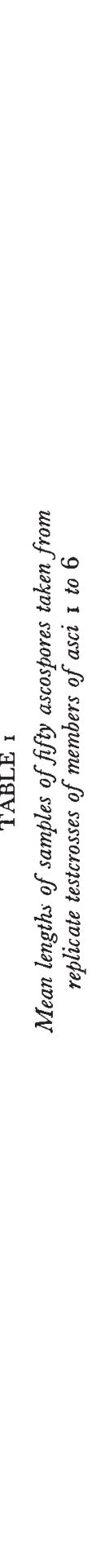 } & ix & 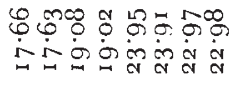 & $1 x$ & 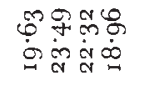 & ix & 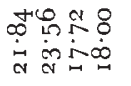 \\
\hline & \multirow{5}{*}{ 芯 } & 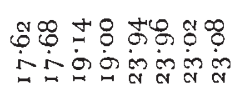 & \multirow{5}{*}{ 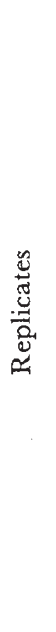 } & 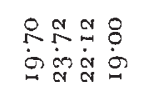 & \multirow{5}{*}{ 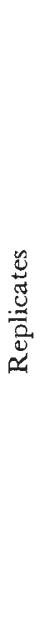 } & 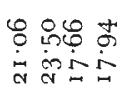 \\
\hline & & 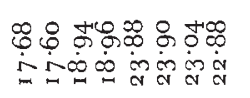 & & 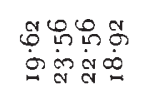 & & 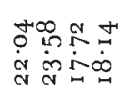 \\
\hline & & 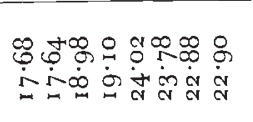 & & 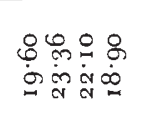 & & 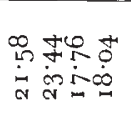 \\
\hline & & 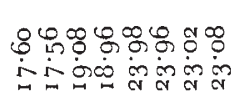 & & 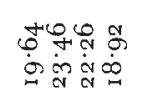 & & 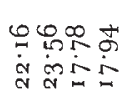 \\
\hline & & 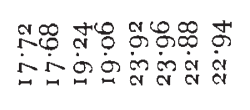 & & 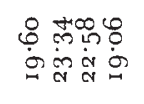 & & 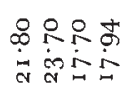 \\
\hline & 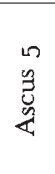 & 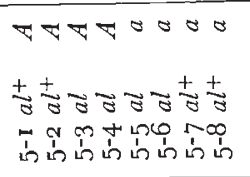 & 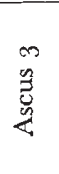 & 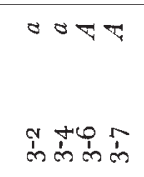 & 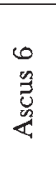 & 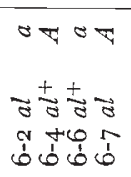 \\
\hline & ix & 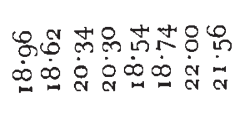 & ix & 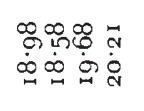 & $B$ & 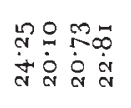 \\
\hline & & 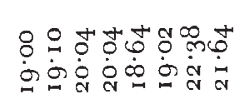 & & 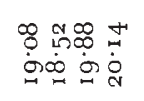 & & 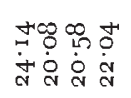 \\
\hline & & 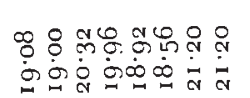 & & 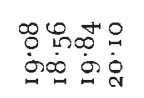 & & 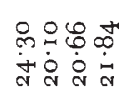 \\
\hline & 怤 & 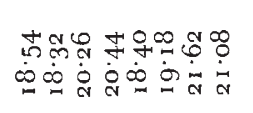 & 㢣 & 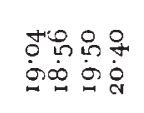 & 苋 & 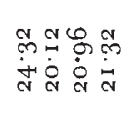 \\
\hline & & 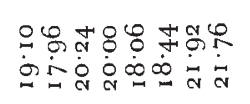 & & 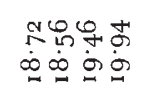 & & 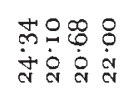 \\
\hline & & 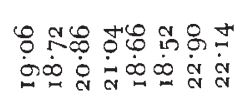 & & 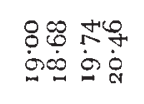 & & 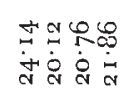 \\
\hline & चै & 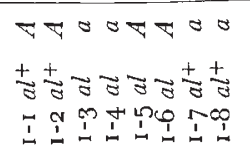 & 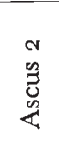 & 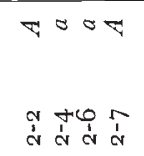 & 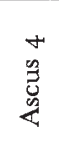 & 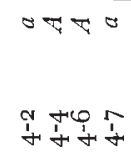 \\
\hline
\end{tabular}


albino locus, $a l^{+}$and $a l$. Both the mating type and albino alleles show the expected $2: 2$ segregation in each ascus. Those strains in each ascus carrying the $a$ allele were testcrossed to 232-2 $A$ and those carrying the $A$ allele were testcrossed to 232-4 $a$.

Inspection of table I shows that there was little variation between replicates or between the means of strains from the same mitotic pair. By comparison there were large differences between some strains which were derived from different meiotic products within the same ascus.

\section{STATISTICAL ANALYSIS}

\section{(i) Segregation and recombination of polygenes}

The analyses of variance of the testcross data are given in table 2. There are seven degrees of freedom for comparisons between the eight members of asci I and 5. There are several ways in which the seven degrees of freedom may be partitioned to give orthogonal sets of comparisons which have some biological significance. The most useful set is that given in table 2. This gives a comparison between the members of each mitotic pair, a comparison between the two halves of the ascus and two comparisons between different meiotic products. Similarly the most useful set of orthogonal comparisons utilising the three degrees of freedom available in asci 2, 3, 4 and 6 is given in table 2. The analyses show that there were no significant differences between any two members of the same mitotic pair. But there were significant differences in most of the comparisons between different meiotic products within the same ascus. This demonstrates that segregation of polygenes effecting ascospore length occurred during the six meiotic divisions which resulted in asci 1 to 6 .

In the analyses of variance the number of comparisons possible was limited by the degrees of freedom available and the necessity that the comparisons should be orthogonal. It would be preferable if comparisons between the two members of each mitotic pair and all the possible comparisons between different meiotic products of an ascus could be made. It is possible to make all the desirable comparisons within each ascus by a series of $t$ tests. The results of such tests are given in table 3 . The $t$ tests indicate that there was no significant difference between members of the mitotic pair, but in the majority of cases the difference between different meiotic products was significant.

There is some doubt concerning the independence of members of a multiple set of $t$ tests such as those given in table 3. A number of authors have proposed methods for dealing with this kind of problem. In particular, Duncan (i 955 ) has developed a " new multiple range test" which, it is claimed, enables independent comparisons to be made between all members of a set of means. The results of the application of this method are given in table 4 . The conclusions which can be drawn from this method are in close agreement with those of the analyses of variance and the $t$ tests. 
TABLE 2

Analyses of variance of testcross data from table $\mathbf{I}$






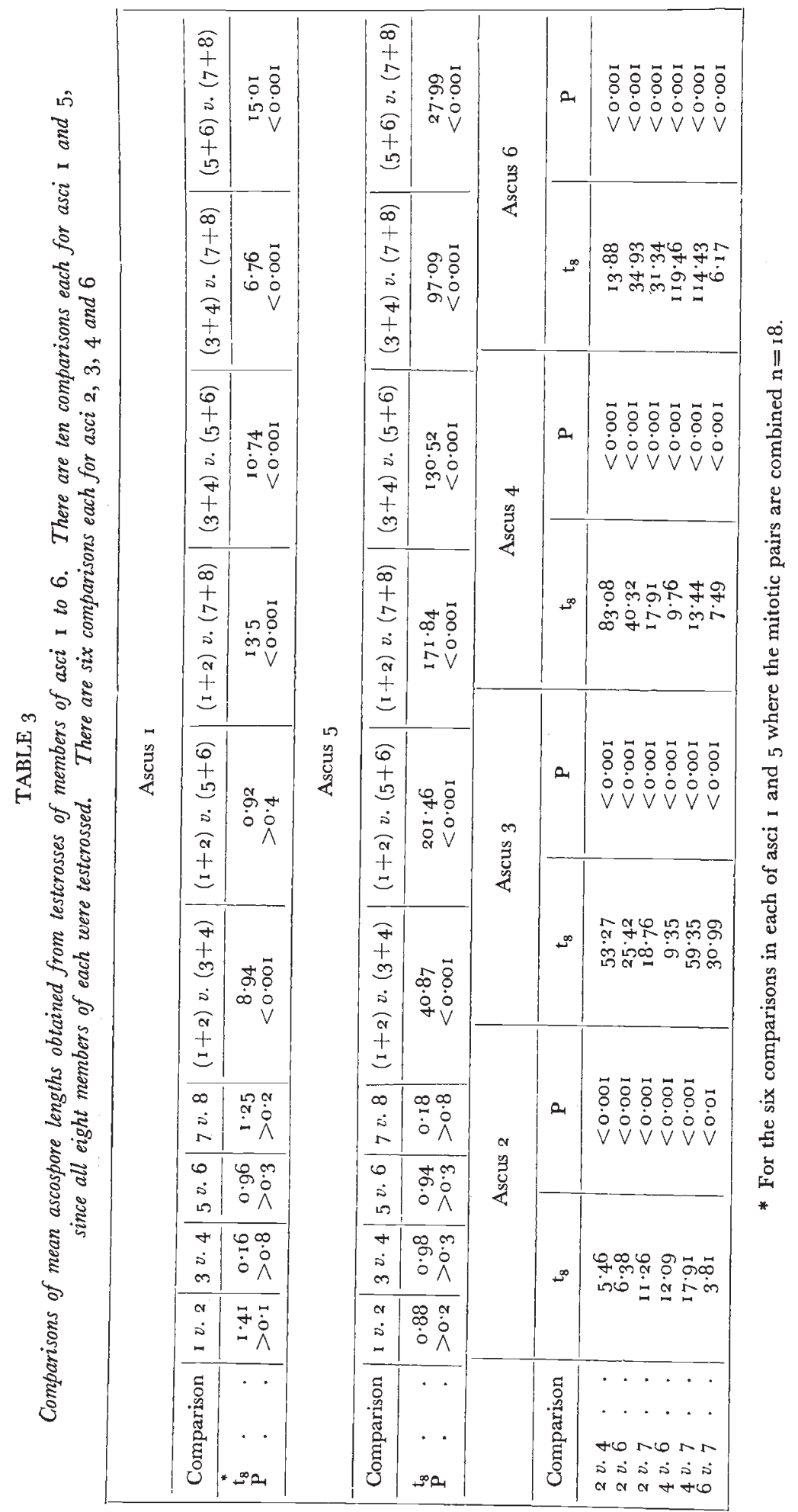


In effect the crossing procedure described means that the genotypes of the members of an ascus are assayed against the genotypic background of the tester strains 232-2 and 232-4. It was necessary to use two tester strains of different mating type. Neurospora crassa is heterothallic and the mating type alleles $A$ and $a$ segregated I : I in each ascus. Ideally, the tester strains should have been isogenic except for the mating type alleles. In practice, strains $232-2$ and $232-4$ were the best available.

\section{TABLE 4}

Analysis by " new multiple range test" of differences between strain means in asci $\mathbf{1}$ to 6 . Any two means not underscored by the same line are significantly different at I per cent. level

\begin{tabular}{|c|c|c|c|c|c|c|c|c|}
\hline \multicolumn{9}{|c|}{ Ascus I } \\
\hline $\begin{array}{l}\text { Strain number } \\
\text { Strain means ranked }\end{array}$ & $\begin{array}{c}7 \\
22 \cdot 00 \\
\end{array}$ & $\begin{array}{r}8 \\
21 \cdot 56 \\
\end{array}$ & $\begin{array}{c}3 \\
20 \cdot 34 \\
\end{array}$ & $\begin{array}{c}4 \\
20 \cdot 30 \\
\end{array}$ & $\begin{array}{c}\mathrm{I} \\
\mathrm{I} 8 \cdot 96 \\
\end{array}$ & $\begin{array}{c}6 \\
\mathrm{I} 8 \cdot 74 \\
\end{array}$ & $\begin{array}{c}2 \\
18.62 \\
\end{array}$ & $\begin{array}{c}5 \\
18 \cdot 54 \\
\end{array}$ \\
\hline \multicolumn{9}{|c|}{ Ascus 5} \\
\hline \multirow{2}{*}{$\begin{array}{l}\text { Strain number } \\
\text { Strain means ranked } \\
\text { in order }\end{array}$} & $\begin{array}{r}5 \\
23 \cdot 94 \\
\end{array}$ & $\begin{array}{r}6 \\
23 \cdot 91 \\
\end{array}$ & $\begin{array}{r}8 \\
22 \cdot 97 \\
\end{array}$ & $\begin{array}{c}7 \\
22 \cdot 96 \\
\end{array}$ & $\begin{array}{c}3 \\
19 \cdot 07 \\
\end{array}$ & $\begin{array}{c}4 \\
\mathrm{I} 9 \cdot \mathrm{O} I \\
\end{array}$ & $\begin{array}{c}1 \\
17 \cdot 66 \\
\end{array}$ & $\begin{array}{c}2 \\
17 \cdot 63 \\
\end{array}$ \\
\hline & \multicolumn{4}{|c|}{ Ascus 2} & \multicolumn{4}{|c|}{ Ascus 3} \\
\hline \multirow{2}{*}{$\begin{array}{l}\text { Strain number } \\
\text { Strain means ranked } \\
\quad \text { in order }\end{array}$} & $\begin{array}{c}7 \\
20 \cdot 2 \mathrm{I} \\
\end{array}$ & $\begin{array}{c}6 \\
19 \cdot 68 \\
\end{array}$ & $\begin{array}{l}2 \\
18 \cdot 98 \\
\end{array}$ & $\begin{array}{l}4 \\
\text { I } 8 \cdot 58 \\
\end{array}$ & $\begin{array}{c}4 \\
23 \cdot 48 \\
\end{array}$ & $\begin{array}{c}6 \\
22 \cdot 32 \\
\end{array}$ & $\begin{array}{c}2 \\
\mathbf{I} 9 \cdot 63 \\
\end{array}$ & $\begin{array}{l}7 \\
18 \cdot 96 \\
\end{array}$ \\
\hline & \multicolumn{4}{|c|}{ Ascus 4} & \multicolumn{4}{|c|}{ Ascus 6} \\
\hline $\begin{array}{l}\text { Strain number } \\
\text { Strain means ranked } \\
\quad \text { in order }\end{array}$ & $\begin{array}{c}2 \\
24 \cdot 24 \\
\end{array}$ & $\begin{array}{r}7 \\
2 \mathrm{I} \cdot 8 \mathrm{I} \\
\end{array}$ & $\begin{array}{c}6 \\
20 \cdot 72 \\
\end{array}$ & $\begin{array}{c}4 \\
20 \cdot 10 \\
\end{array}$ & $\begin{array}{r}4 \\
23 \cdot 56 \\
\end{array}$ & $\begin{array}{r}2 \\
21 \cdot 83 \\
\end{array}$ & $\begin{array}{l}7 \\
18 \cdot 00 \\
\end{array}$ & $\begin{array}{c}6 \\
17 \cdot 72 \\
\end{array}$ \\
\hline
\end{tabular}

Samples of ascospores were measured from backcrosses to the largespored parent of $\mathrm{I}_{7} \mathrm{~F}_{1}$ strains obtained from crosses between 232-2 and 232-4 and stock wild-types (B. T. O. Lee, unpublished). The results showed that there were no significant genotypic differences between 232-2 and 232-4 with respect to ascospore size. If, however, there was such a genotypic difference between $232-2$ and $232-4$ it could not have been responsible for all of the observed differences between the testcrosses of members of the same ascus. From each ascus two of the meiotic products were testcrossed to 232-2 and the other two to 232-4. Thus it is possible to compare two members of an ascus which have been testcrossed to the identical strain. There 
are twelve such comparisons possible, two in each of the six asci. For example, $3-2 \times 232-2$ versus $3-4 \times 232-2$ and $3-6 \times 232-4$ versus $3-7 \times 232-4$ from ascus 3 . It can be seen from the multiple range test of all six asci that eleven of the twelve possible comparisons are significant at the I per cent. level. In none of these eleven comparisons could the observed significant differences be due to any difference between 232-2 and 232-4. The differences must have been due to genotype differences between different meiotic products within the same ascus.

\section{(ii) Interaction of polygenes}

Asci 5 and 6 were derived from the same cross and asci 2, 3 and 4 were derived from the same cross. This means that asci 5 and 6 were derived by separate meiotic divisions from identical diploid nuclei and asci 2, 3 and 4 were also the result of separate meiotic divisions of identical diploid nuclei. If the individual effects of the members of this polygenic system were simply additive, then the mean of the four meiotic products of one diploid nucleus should be approximately equal to the mean of the meiotic products of a second identical diploid nucleus. But the differences between the four meiotic products of a diploid nucleus will depend on the particular combinations of polygenes carried by each meiotic product. It was possible to make four such comparisons between the combined means of the meiotic products from identical nuclei: ascus 2 versus ascus 3,2 versus 4,3 versus 4 and 5 versus 6 . The analyses of variance which enabled the appropriate comparisons to be made are given in table 5 . It can be seen that the differences between the asci in all four comparisons are significant. Therefore the polygenes in this system interact in their effects on ascospore length. The magnitude of this interaction may be quite large. The mean ascospore length of the largest member of ascus 2 was approximately equal to that of the smallest member of ascus 4 . The mean ascospore length obtained from all members of ascus 2 was I $9 \cdot 36$, the mean length from all members of ascus 4 was $21 \cdot 72$, a difference of $2 \cdot 36$.

\section{DISCUSSION}

The experiments described showed that there was no detectable genetic difference with respect to ascospore length in strains which were the result of a single mitosis. In comparison there were many instances of large and significant genetic differences between strains which were derived from different products of a single meiotic division. This behaviour of the genetic material effecting ascospore length parallels that of the Mendelian alleles, $a, A$ and $a l$, $a l^{+}$, which were also segregating during the formation of the ascospores. It is clear that the polygenes concerned segregated and recombined during single meiotic divisions in a similar fashion to Mendelian genes. This confirms the view first proposed by Nilsson-Ehle (I909), East (I9I5) 


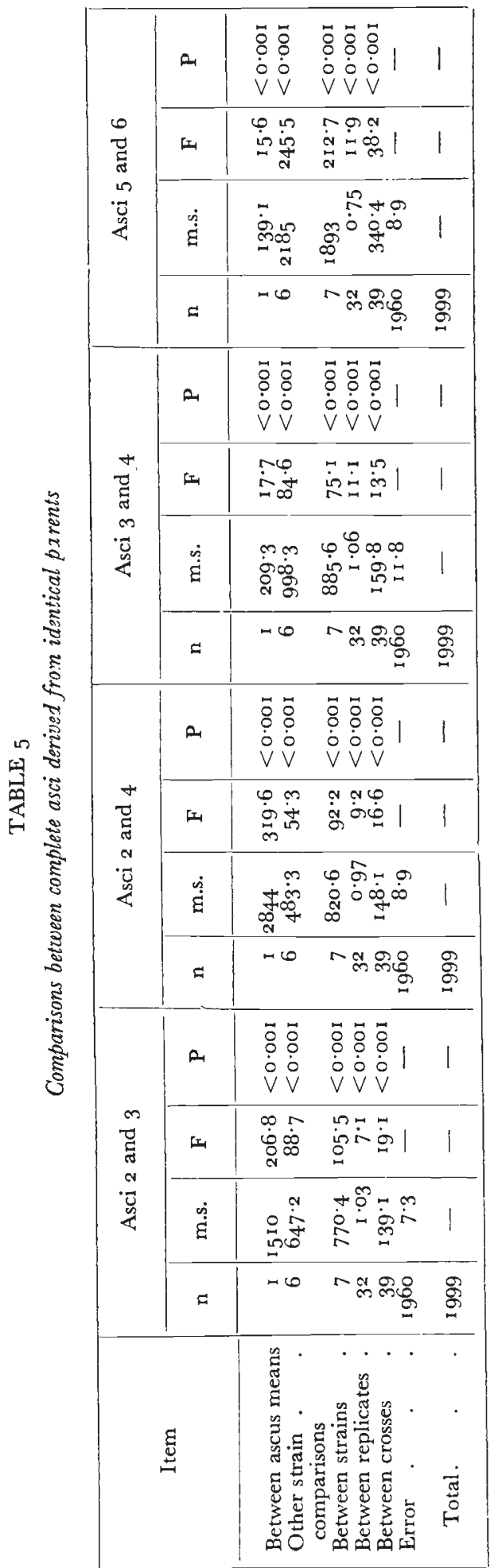


and developed by Fisher (I918) and Mather (1949). Namely, continuous quantitative variation can be explained by genetic factors of small individual effects which segregate and recombine in a similar fashion to major genes. Previous experimental demonstration of the segregation of multiple factors or polygenes was indirect. It depended essentially on the relative variation of different generations in certain breeding programmes, notably the usually observed increase of variance in the $\mathrm{F}_{2}$ generation.

The phenotypic effects of polygenes and Mendelian genes differ in magnitude, but there is no reason to suppose that this is due to any fundamental differences in the characteristics of the genetic material of which they are composed. It is probable that polygenes and major genes represent opposite ends of a continuous spectrum of possible gene effect. In the polygenic system effecting ascospore length in Neurospora crassa the phenomena of dominance, (Pateman, I959), linkage (Lee and Pateman, I959) and in the present work segregation, recombination, and gene interaction have all been demonstrated. This evidence supports the hypothesis that polygenic and major gene variation are fundamentally similar in nature.

\section{SUMMARY}

I. It has been established previously that the genetic determination of ascospore length in Neurospora crassa is chiefly polygenic. From a cross between a normal strain and a strain whose genotype was known to determine increased ascospore length, $F_{1}$ strains were obtained. From backcrosses between $F_{1}$ strains and the large-spored strain, six complete asci were isolated and dissected. The member strains of each ascus were backcrossed to the large-spored strain and the mean length of samples of the ascospore progeny obtained. The second backcrosses provided an estimate of the genotypes, with respect to the determination of ascospore length, of each single ascospore strain from each ascus.

2. Analysis of the backcross data enabled the following conclusions to be drawn: There were no significant differences, with respect to mean ascospore length, between strains derived from a single mitotic division. In many instances there were significant differences, with respect to mean ascospore length, between strains derived from different products of the same meiotic division. There were significant differences, with respect to mean ascospore length, between the total means obtained from separate asci, where each ascus had been derived by a single meiosis from identical diploid nuclei.

3. The results provided a direct demonstration of the segregation and recombination of polygenes during single meiotic divisions. They also showed that the phenotypic effects of the polygenes effecting ascospore length were not simply additive, there was a considerable amount of gene interaction. 


\section{POLYGENES IN TETRADS}

\section{REFERENCES}

BEAdLE, G. W., AND TATUM, E. L. I945. Methods of producing and detecting mutations concerned with nutritional requirements. Amer. F. Bot., 32, 678-686. DUNGAN, D. B. I955. Multiple range and multiple $\mathrm{F}$ tests. Biometrics, II, I-42. EAST, E. M. I9I5. Studies on size inheritance in Nicotiana. Genetics, I, I64-76.

FISHER, R. A. I9I8. The correlation between relatives on the supposition of Mendelian inheritance. Trans. Roy. Soc. Edin., 52, 399-433.

LEE, B. T. O., AND PATEMAN, J. A. I959. Linkage of polygenes controlling size of ascospore in Neurospora crassa. Nature, Lond., 183, 698-699.

MATHER, K. 1949. Biometrical Genetics. Methuen, London.

NILSSON-EHLE, H. I909. Kreuzungsuntersuchungen an Hafer und Weizen. Lund. pateman, J. A. I955. Polygenic inheritance in Neurospora. Nature, Lond., I76, I $274-$ I 275 .

Pateman, J. A. I959. The effect of selection on ascospore size in Neurospora crassa. Heredity, 13, I-2I.

WestergaARD, M., AND MTCHell, H. K. I947. Neurospora V. A synthetic medium favouring sexual reproduction. Amer. F. Bot., 34, 573-577. 